\title{
Bilateral multiple cavities in bronchiolar carcinoma
}

\author{
TAKASHI NAKANO, SHINSUKE TAMURA, TOSHIKAZU HADA, \\ KAZUYA HIGASHINO
}

\section{From the Third Department of Internal Medicine, Hyogo College of Medicine, Nishinomiya, Japan}

Single cavities are well recognised in bronchiolar carcinoma, but bilateral multiple cavities have rarely been reported. We describe a case of bronchiolar carcinoma presenting with bilateral multiple cavities.

\section{Case report}

A 52 year old woman was admitted to hospital because of increasing cough and dyspnoea. Mild dyspnoea and a cough had developed two years earlier and subsequently increased in severity, with the production of copious whitish sputum. Twenty months before admission a chest radiograph showed homogeneous consolidation in the anterior segment of the right upper lobe (fig 1). Physical examination showed rhonchi in both lungs and anterior cervical and supraclavicular lymphadenopathy ( $<1 \mathrm{~cm}$ in diameter). Digital tomography of the chest showed bilateral multiple cavities with areas of ill defined consolidation and air bronchograms (fig 2). Repeated cytological examination of sputum detected no malignant cells and no pathogenic organisms were isolated from cultures. Bronchoscopy showed diffuse redness of the bronchial mucosa but no endobronchial lesion. Transbronchial biopsy specimens from the anterior branch of the right upper lobe bronchus and the inferior branch of the lingular bronchus showed bronchiolar carcinoma histologically. Alveolar architecture was preserved but the alveolar spaces were lined with mildly pleomorphic cuboidal or columnar tumour cells.

\section{Discussion}

Of 100 patients with cavitating lung carcinoma, 92 had a single cavity and the remainder multiple cavities. Eighty two were squamous cell carcinoma, 11 undifferentiated large cell carcinoma, four adenocarcinoma, and three alveolar cell carcinoma.' Analysis of the radiographic features in 153 patients with bronchiolar carcinoma showed a solitary nodule in $26 \%$ and bilateral multiple nodules in $20 \% ; 8 \%$ of the patients had pleural effusion and $16 \%$ had consolidation of all or part of a lobe but none was recorded as having cavitation. ${ }^{2}$ A single nodule with cavitation was observed in two of 41 patients with bronchiolar carcinoma. ${ }^{3}$ And a single cavity was recorded in $7 \%$ of 122 patients in a further study. ${ }^{4}$ The presence of bilateral multiple cavities in bronchiolar carcinoma is very rare, with only five reported cases. ${ }^{6-10}$

The pathogenesis of the relatively large numbers of cavities in bronchiolar carcinoma is unknown, though it has been

Address for reprint requests: Dr Takashi Nakano, Third Department of Internal Medicine, Hyogo College of Medicine, 1-1, Mukogawacho, Nishinomiya City, Hyogo 663, Japan.

Accepted 10 July 1987

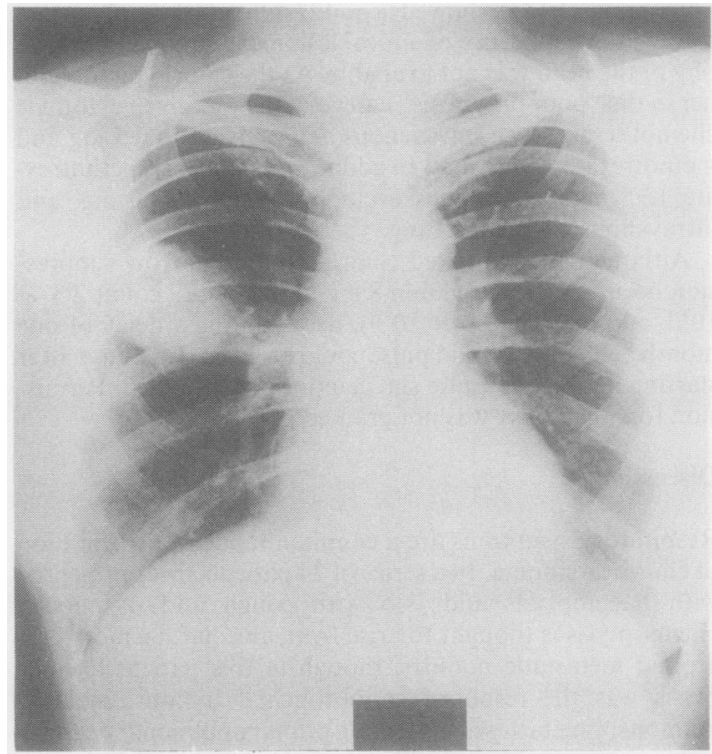

Fig 1 Radiograph of the chest taken 20 months before admission, showing a solitary homogeneous consolidation of the anterior segment of the right upper lobe.

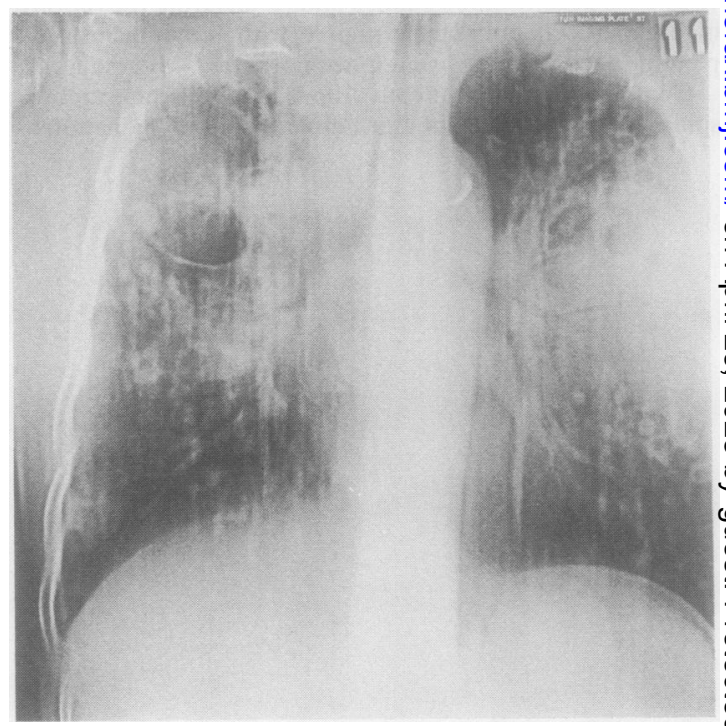

Fig 2 Digital tomogram of the chest showing multiple cavities, air bronchograms and diffuse, ill defined opacities. 
suggested that terminal bronchioles thickened by infiltration with tumour act as check valves and cause emphysematous cystic spaces to develop in the lobules. ${ }^{8}$ In some instances of multiple cavitation the neoplasm could have invaded preexisting cysts, but this could not account for the present case because the earlier chest radiograph showed no evidence of bullae or bronchiectasis.

The number of patients with cavitating bronchiolar carcinoma is small, but bilateral multiple cavities with ill defined consolidation can occur.

\section{References}

1 Chaudhuri MR. Primary pulmonary cavitating carcinomas. Thorax 1973;28:354-66.

2 Storey CF, Knudson KP, Lawrence BJ. Bronchial (alveolar cell) carcinoma of the lung. J Thorac Surg 1953;26:331-403.

3 Ludington LG, Verska JJ, Howard T, Kypridakis G, Brewer LA.
Bronchiolar carcinoma (alveolar cell), another great imitator: a review of 41 cases. Chest 1972;61:622-8.

4 Greco RJ, Steiner RM, Goldman S, et al. Bronchoalveolar cell carcinoma of the lung. Ann Thorac Surg 1986;41:652-6.

5 Marzano MJ, Deschler T, Mintzer RA. Alveolar cell carcinoma. Chest 1984;86:123-8.

6 Berkmen YM. The many faces of bronchiolo-alveolar carcinoma. Semin Roentgenol 1977;12:207-14.

7 Wormer DC. Cavitary bronchiolar carcinoma. Am Rev Respir Dis 1969;99:773-6.

8 Ohba S, Takashima T, Hamada S, Katagawa M. Multiple cystic cavitary alveolar cell carcinoma. Radiology 1972;104:65-6.

9 Seki Y, Fukuma S, Sawada K, et al. Bronchioloalveolar cell carcinoma: report of an autopsy case with 21-year clinical history followed by chest $x$-ray examination [abstract]. J Japan Lung Ca Soc (Lung Cancer) 1980;20:59-64.

10 Higashiguchi $R$, Katada $H$, Ueno $M$, et al. A case of bronchioloalveolar type papillary adenocarcinoma presenting with multiple cavities [abstract]. J Japan Lung Ca Soc (Lung Cancer) 1984;24:743-8. 